chemical structure with no apparent relationship at all to either iproniazid or $\beta$-phenyl isopropylhydrazine except for its ability to inhibit monoamine oxidase.

The findings with three chemically different inhibitors - the hydrazines, the choline ether and harmine-would tend to give some support to the hypothesis that the inhibition of monoamine oxidase results in ganglionic blockade, if it could be shown that the block of transmission is always correlated with the inhibition of monoamine oxidase in the ganglion. The implication, if this be true, is that a substance is accumulating at the ganglion which can inhibit transmission and which would appear to have a function in transmission. Some evidence for such a hypothesis is that with low concentrations of the inhibitors, the block of transmission develops gradually and increases in magnitude with time. This can be contrasted with hexamethonium blockade which is immediate.

Experiments are proceeding to elucidate the mechanism of the block produced by monoamine oxidase inhibitors.

Dept. of Pharmacology,

Sheldon B. Gertner

Seton Hall College of Medicine,

Jersey City 4, New Jersey. Dec. 24.

${ }^{1}$ Cesarman, T., Conf, Amine Oxidase Inhibitors, New York Academy of Sciences (Nov. 20-22, 1958)

${ }^{2}$ Hollander, W., Symp. Hypertension. Hahnemann Medical College and Hospital, Philadelphia (Dec. 8-12, 1958).

${ }^{3}$ Gertner, S., Paasonen, M., and Giarman, N. J., Fed. Proc., 16, 1281 (1956).

4 Horita, A., J. Pharmacol., 122, 176 (1958).

${ }^{5}$ Udenfriend, S., and Weissbach, H., Proc. Soc. Exp. Biol, and Med., 97, $748(1958)$

${ }^{6}$ Zeller, E. A., and Barsky, J., Proc. Soc. Exp. Biol. and Med., 81, 459 (1952)

\section{Preparation of Caruloplasmin from the G2 Fraction of Human Plasma}

THE recent publication of a communication on the preparation of cæruloplasmin ${ }^{1}$, the main cuproprotein of plasma, prompts this brief account of a method of its preparation from the precipitate $G 2$, the mixture of $\alpha$-and $\beta$-globulins obtained in the plasma fractionation scheme of Kekwick and Mackay². With ${ }^{2} 2$ from batehes of plasma of $40-150 \mathrm{l}$,, the following stages were used : (1) Extraction of $G 2$ by $0.07 M$ sodium chloride at $p \mathrm{H} 7$ and denaturation of extracted lipoprotein with ether below $-25^{\circ} \mathrm{C}$. by the McFarlane technique ${ }^{3} ;(2)$ precipitation of cæruloplasmin from the ether-saturated extract at $p \mathbf{H} 4.8$; (3) solution of the precipitate in ether-saturated $0.1 M$ sodium chloride, removal of impurities by precipita. tion at $p H 5.35$ and a second McFarlane treatment; (4) reprecipitation of cæruloplasmin at $p \mathrm{H} 4.8$ as in (2) and solution in $0.1 M$ sodium chloride; (5) precipitation of impurities at $p \mathbf{H} 4 \cdot 8$ by diluting to $0.02 M$ sodium chloride and precipitation of cæruloplasmin by further dilution to $0.0045 M$ sodium chloride. The product was dissolved in $0 \cdot 1 M$ sodium chloride. $E_{1 \mathrm{~cm} .}(605 \mathrm{~m} \mu) / E_{1 \mathrm{~cm} .}(280 \mathrm{~m} \mu)$, which gives a measure of degree of purification, was 0.019 .

About 45 per cent of the oxidase activity of the initial extract was recovered. Stages 2 and 4 resulted in concentration rather than purification. They were necessary to reduce working volumes in the large-scale work described here, but presumably could be omitted in smaller-scale work. Further purification to $E_{1 \mathrm{~cm} .}(605 \mathrm{~m} \mu) / E_{1 \mathrm{~cm} .}(280 \mathrm{~m} \mu)=0.033$ was possible using a batch adsorption method with diethylaminoethylcellulose ('DEAE' Kodak). Cærulo- plasmin was adsorbed on the diethylaminoethyl cellulose from $0 \cdot 05 M, p \mathbf{H} 5 \cdot 7$, sodium acetate buffer with $0.08 M$ sodium chloride and eluted by $0.05 M$, $p H 5 \cdot 2$, sodium acetate buffer with $0 \cdot 25 M$ sodium chloride. Greater purification of the product of stage 5 was attained on a diethylaminoethylcellulose column with an elution gradient from $0.05 \mathrm{M}, p \mathrm{H} 5 \cdot 7$ sodium acetate buffer with $0.10 \mathrm{M}$ sodium chloride to $0.05 M, p \mathrm{H} 5 \cdot 2$, sodium acetate buffer with $0.25 M$ sodium chloride, using a constant-rolume mixing chamber. Bulked eluate fractions were chromatographed again on a similar column. The product had a copper/nitrogen ratio of $0.0197 \mathrm{w} / \mathrm{w}$

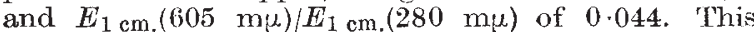
compares well with the ratio of 0.042 of purified cæruloplasmin prepared by Morell and Scheinberg*. The purification was performed at $2-4^{\circ} \mathrm{C}$., excepting the column chromatography, which was done at room temperature. Freeze-drying of cæruloplasmin preparations resulted in partial loss of oxidase activity and markedly altered absorption spectra in the visible range unless exceptionally rapid freezing on $0.1 \mathrm{M}$ sodium chloride was used. Freeze-drying from as salt. free solution under the same conditions caused partial inactivation. It is of interest that the cuproprotein hæmocyanin (Busycon canaliculatum and Limulus polyphemus) is also fragile under freeze-drying onnditions ${ }^{5}$.

The advantages of the method are that the raw material $G 2$ is plentiful, being usually discarded in the preparation of gamma globulin for clinical use ; and that relatively mild $p \mathrm{H}$ and solvent conditions are used throughout. The method is suitable for large-scale work. This investigation will be described more fully elsewhere.

We thank Dr. D. R. Kominz for making available to us unpublished results on the purification of cæruloplasmin. One of us (G. C.) thanks the Research Advisory Committee of the Institute of Neurology for financial support.

Department of Chemical Pathology,

G. CTRZON

Institute of Neurology,

London, W.C.1.

Blood Products Laboratory,

L. VALLET

Lister Institute,

Elstree, Herts.

Feb. 11

1 Steinbuch, Mr, and Quentin, M., Nature, 183, 323 (1959).

${ }^{2}$ Kekwick, R. A., and Mackay, M. E., Hedical Research Council Spec Rep No. 286 (1954).

${ }^{3}$ McFarlane, A. S., Nature, 149, 439 (1942)

- Morell, A. G., and Scheinberg, I. H., Science, 127, 588 (1958)

${ }^{5}$ Litt, M., and Boyd, W. C., Nature, 181, 1075 (1958).

\section{Effects of Pyridoxine Withdrawal on Cerebral Circulation and Metabolism in a Pyridoxine-dependent Child}

RECEN'T studies have established a relationship between vitamin $\mathbf{B}_{6}$ metabolism and convulsive disorders of the nervous system. Pyridoxine deficiency in young animals and human infants and the administration of pyridoxine antagonists in animals have been observed to cause convulsive activity which is rapidly alleviated by administration of pyridoxine ${ }^{1,2}$. Several instances have been reported of children with abnormally high vitamin $B_{6}$ requirements ${ }^{1,3}$. On ordinary dietary vitamin $\mathbf{B}_{6}$ intake, they appear, at least as regards their nervous system, 